\title{
Interpersonal Relationships as Protective and Risk Factors for Psychopathy : A Follow-up Study in Adolescent Offenders
}

\section{Backman, Heidi}

2018-05

Backman , H , Laajasalo , T , Jokela , M \& Aronen , E T 2018 , ' Interpersonal Relationships as Protective and Risk Factors for Psychopathy : A Follow-up Study in Adolescent Offenders ' , Journal of Youth and Adolescence , vol. 47 , no. 5 , pp. 1022-1036 . https://doi.org/10.1007/s10964-017-0745-x

http://hdl.handle.net/10138/311408

https://doi.org/10.1007/s10964-017-0745-x

acceptedVersion

Downloaded from Helda, University of Helsinki institutional repository.

This is an electronic reprint of the original article.

This reprint may differ from the original in pagination and typographic detail.

Please cite the original version. 


\title{
Interpersonal Relationships as Protective and Risk Factors for Psychopathy: A Follow-up Study in Adolescent Offenders
}

\author{
Heidi Backman, Taina Laajasalo, Markus Jokela, Eeva T. Aronen
}

\begin{abstract}
Friendships and romantic relationships may function as protective and risk factors for psychopathic traits. To better understand potential causal associations, we investigated whether within-individual changes in relationship characteristics were related to changes in psychopathic traits over time. Data were derived from ten repeated measurements of the Pathways to Desistance longitudinal study of 1354 offending adolescents (14.3\% female; $40.1 \%$ Black). Analyses were adjusted for age, gender, ethnicity, self-reported offending and living facilities. Relationships of high quality were associated with lower psychopathic traits, whereas antisocial behavior and antisocial influence in relationships were related to higher psychopathic traits. Within-individual analysis indicated that time-invariant individual characteristics did not confound these associations. The findings suggest that the quality and antisocial activities of interpersonal relationships can affect positively or negatively on the levels of psychopathy.
\end{abstract}

\section{Introduction}

Psychopathy is characterized as a set of affective, interpersonal and behavioral domains that manifest as callousness, shallow affect, lack of remorse, manipulativeness, a grandiose sense of 
self-worth, glibness, impulsivity, and irresponsibility (Blair 2013; Cleckley 2016). Similar to those recognized in adults, the three domains of psychopathy-affective, interpersonal, behavioral-are also observed in adolescents (Frick 2009; Lynam and Gudonis 2005). The affective, and especially the so-called callous-unemotional (CU) traits, have been regarded as the central characteristic of psychopathy, designating a violent, and the most delinquent, subgroup among adolescents (Frick et al. 2014; Muñoz et al. 2008; Ray et al. 2017). The purpose of the study is to extend the body of work of psychopathy by searching for protective factors. The approach to investigate psychopathy before adulthood should be proactive rather than reactive in order to improve health and reduce violence at the community and societal levels (see Reidy et al. 2015).

From childhood to adolescence, levels of psychopathic traits tend to be moderately stable (Barry et al. 2008; Lynam et al. 2007; Lynam and Gudonis 2005) followed by a decrease in early adulthood (Frick et al. 2003; Hawes et al. 2014; Lynam and Gudonis 2005). However, at a rankorder level, psychopathic traits are highly stable (Bergstrøm et al. 2016). A similar trend can been seen with delinquency (Farrington 1986; Moffitt 1993; Zedaker and Bouffard 2017). While most adolescents with high psychopathic levels improve and exhibit less severe levels of these traits in young adulthood, for some individuals, the levels of psychopathic traits remain elevated, developing into a persistent personality disorder (Frick et al. 2003; Lynam et al. 2008; Reidy et al. 2015). For example, Lynam et al. (2007) detected that less than a fifth of those scoring in the top $20 \%$ on psychopathic measures at age 13 were psychopathic at age 24 . This makes the study of protective and risk factors in adolescence and young adulthood particularly important.

Although psychopathic traits are strongly influenced by genetic factors (e.g., Blair 2013), social factors are also involved in the emergence of psychopathic traits (e.g., Reidy et al 2015). 
In studies longitudinally examining social precursors of psychopathy, the main focus has been in the risks for developing psychopathy rather than in precursors promoting a positive outcome, either by reducing the level of psychopathic traits or minimizing their negative consequences (see DeMatteo et al. 2005; Salekin et al. 2010). As Salekin and Lochman (2008) stated, it is time to uncover protective factors that foster prosocial, healthy behavior and deter individuals from developing a persistent psychopathic or antisocial personality. These factors may reduce psychopathy and criminality simultaneously (Caldwell et al. 2012) and, accordingly, confer a benefit to both the individual and the community. The ability to change in adolescence, particularly, needs to be exploited because adolescents are more responsive to improvement and less likely to have prolonged prior incarcerations compared to adults (Lynam et al. 2007; Salekin et al. 2010). Although psychopathy has been considered impossible to treat, there is preliminary positive evidence of certain interventions targeted to adolescents (Reidy et al. 2015). This effect may relate to the developmental phase of adolescence, in which dopaminergic activity and oxytocin transmission are changing and prefrontal areas of the brains are still maturing, allowing sensitivity to certain emotional and behavioral functions such as emotional stimuli, rewards and novelty (Colver and Longwell 2013).

The adolescent social environment may be one potential area for intervention in order to lower psychopathic characteristics. Peer process variables may have substantial role by mediating effects between contextual factors and antisocial behavior in adolescence (Capaldi et al. 2002). Studies have already confirmed that a prosocial peer group may prevent later offending (Hemphill et al. 2015; Shepherd et al. 2016), but investigations regarding protective roles of social relationships on psychopathic traits are scarce. Besides positive parental practices (see Waller et al. 2013), higher social functioning and prosocial peer relationships may have 
protective effects on psychopathic-like behavior according to Barry et al. (2008), and having at least one school friend may reduce delinquent acts by youth with high psychopathic traits according to Muñoz et al. (2008). Also, positive peer support and strong commitment to school appear to have ameliorating effects of risk (Fanti et al. 2017). In contrast, three other studies (Kimonis et al. 2004; Kokkinos et al. 2016; Pardini and Loeber 2008) failed to find a significant correlation between prosocial peer groups and reduction in CU traits among youth.

There is a positive correlation between deviant peers and psychopathic characteristics (Lynam et al. 2008; Muñoz et al. 2008; Tatar et al. 2016), and the causality appears to be bidirectional (Kerr et al. 2012; Kimonis et al. 2004; Van Zalk and Van Zalk 2015). Psychopathic individuals are more likely to offend with peers than alone (Muñoz et al. 2008; Thornton et al. 2015) and to experience lower peer support (Fanti 2013; Fanti et al. 2017) and problems in their friendships in general (Kokkinos et al. 2016; Muñoz et al. 2008). Although low social support correlates with high CU traits (Fanti 2013), Muñoz et al. (2008) reported that peers of psychopathic adolescents may perceive their friendships as supportive and low in conflict. This finding reflects the complexity of the dynamics of interpersonal relationships in adolescence. On the other hand, having no friends may be adverse to the individual as well. For example, social isolation can act as a risk factor for developing psychopathic features (Lynam et al. 2007) or other psychological health problems (Hall-Lande et al. 2007). Peer relationships may thus be a significant factor for psychological health in adolescence. Although current results hint at the benefits of avoiding delinquent peers and favoring prosocial friends in terms of reducing psychopathic features, it is unclear whether these associations are causal or only represent the influence of confounding factors common to both social relationships and psychopathic traits. In fact, many studies conducted among adolescents have stated that, peer delinquency does precede 
psychopathic-like behavior but might not cause it across time (Farrington et al. 2002; Hemphill et al. 2015; Pardini and Loeber 2008). Within-individual analysis of repeated measurements allows one to test whether changes in the risk factor are associated with corresponding changes in psychopathy, which is a stronger test for a causal association.

Besides the importance of peer relationships in the teenage years, adolescence is also a time to start dating and form romantic relationships (Zimmer-Gembeck 2002). The links between romantic relationships and psychopathic traits have not been studied as extensively as the effects of romantic relationships on antisocial behavior. There are still some differing views in the literature as to whether romantic relationships amplify or attenuate a partner's delinquency. There are a number of studies indicating that a deviant partner promotes delinquency persistence (e.g., Haynie et al. 2005; Monahan et al. 2014; Simons et al. 2002), and the promoting mechanism is typically examined in the context of "behavior contagion," referring to a reciprocal effect of problem behavior among intimate partners (Rhule-Louie and McMahon 2007). This contagion effect for antisocial acts can be valid throughout the relationship (Haynie et al. 2005) or solely short-term (Monahan et al. 2014). Eklund and colleagues (2010) demonstrate that romantic partners may enhance pre-existing delinquency, but do not cause subsequent offending, and the impact is more pronounced in early adolescence than later in life. On the other hand, romantic relationships may play a protective role against delinquency, especially for relationships of high quality (Rhule-Louie and McMahon 2007; Zedaker and Bouffard 2017), reflecting strong attachment or bonds (Maume et al. 2005; Sampson and Laub 1995; Warr 1998). For example, Zedaker and Bouffard (2017) found that the higher the quality of a romantic relationship, the less young adult male criminals report offending. It appears that high-quality relationships may deter individuals from problem behavior through psychosocial and peer 
processes (Larson et al. 2016), such as the attachment and social bond to a partner (Sampson and Laub 1995; Sampson et al. 2006), social control or emotional support of the spouse (Wyse et al. 2014), avoidance of wanting to harm the relationship (Haynie et al. 2005) or distancing oneself from delinquent friends (Warr 1998).

In adults, psychopathy correlates negatively with relationship satisfaction (Savard et al. 2006), commitment (Ali and Chamorro-Premuzic 2010) and the need for a long-term relationship (Jonason et al. 2012), and positively with couple distress (Savard et al. 2006). According to Schimmenti and colleagues (2014), having many short-term marital relationships and promiscuous sexual behavior, two items on the Psychopathy Checklist-Revised (PCL-R; Hare 2003), showed associations with psychopathy (i.e., PCL-R total score). More specifically, the affective and interpersonal domains correlated highest with promiscuous sexual behavior, while having many marital relationships was linked most firmly to the behavioral domain. In another study, impulsivity was not associated with the quality of romantic relationships or a partner's antisocial influence (Zedaker and Bouffard 2017). Generally, psychopaths consider their romantic relationships to be poor and their subjective well-being inferior (Love and Holder 2014; 2016). In fact, Love and Holder (2014) suggested that psychopathy's propensity to influence one's subjective well-being may stem from interpersonal relationship quality.

In general, the literature on psychopathic traits in adolescents is hampered by the lack of studies investigating protective factors against psychopathy with appropriate methods. First, interpersonal relationships should be explored as possible preventive factors of psychopathy and all its sub-domains (affective, interpersonal, behavioral). Second, the quality of both peer and romantic relationships should be scrutinized because only a few previous studies have investigated the quality of friendships (Barry et al. 2008; Muñoz et al. 2008) or intimate 
relationships (e.g. Maume et al. 2005; Wyse et al. 2014; Zedaker and Bouffard 2017), and none in the same study, although romantic and peer relationships may be entangled (Haynie et al. 2005; Wright and Cullen 2004; Zedaker and Bouffards 2017). Third, gender differences should be considered because females are generally more susceptible to partner influence on antisocial acts (Eklund et al. 2010; Haynie et al. 2005; Rhule-Louie and McMahon 2007; Simons et al. 2002) although the romantic relationship length and developmental age may moderate the association (Kerig 2014; Monahan et al. 2014). In regards to peer relationships, adolescent boys are more likely than girls to experience lower social support from peers in general, but the opposite might be true in youth with high CU traits (see Fanti 2013). Finally, the causes of psychopathy should be analyzed by examining intra-individual changes over time, as this method adjusts for all of the time-invariant confounding factors that may create spurious correlations in cross-sectional data (Curran and Bauer 2011; Hemphill et al. 2015). Only a few studies have analyzed peer relationships (Barry et al. 2008; Hemphill et al. 2015; Farrington et al. 2002) and romantic relationships (Larson et al. 2016; Monahan et al. 2014; Sampson et al. 2006) by using within-individual analysis.

\section{Current Study}

The goals of this study were (1) to identify the possible predictive roles of romantic relationships on total psychopathic traits as well as its three domains and (2) to examine the causality of peer relationships on psychopathy. Based on the previous literature regarding protective effects of intimate relationships (Maume et al. 2005; Rhule-Louie and McMahon 2007; Zedaker and Bouffard 2017) and peer relationships (Barry et al. 2008; Fanti et al. 2017; Muñoz et al. 2008) as 
well as their negative influences for romantic relationships (Haynie et al. 2005; Monahan et al. 2014) and friendships (Kerr et al. 2012; Van Zalk and Van Zalk 2015), we tested two hypoteheses. First, we hypothesized that romantic relationships of high quality (i.e., subjective ratings of satisfaction, love, closeness and interpersonal support) and friendships of high quality (i.e., subjective ratings of closeness and supportiveness) have protective roles on psychopathic traits. Second, partner's antisocial influence (i.e., suggestiveness for antisocial acts) and peer delinquency (i.e., antisocial activities among peer group) elevate psychopathic traits.

\section{Method}

\section{Participants and Procedure}

The participants of the present study were drawn from the Pathways to Desistance project (Mulvey 2004), a longitudinal, prospective study of 1354 serious felony-offending adolescents (1170 males and 184 females) in two major metropolitan areas, Philadelphia and Phoenix. To be eligible for the Pathways to Desistance study, adolescents had to be between the ages of 14 and 17 at the time they committed the crime, and adjudicated delinquent or found guilty of a serious offense, predominantly felonies. Enrollment began in the year 2000 and was completed in 2010. The participants were followed from adolescence to adulthood with a baseline interview and 10 follow-up interviews every 6 months for 3 years and annually thereafter for 7 years in total. To ensure equal measurement periods for all participants, windows of opportunity for follow-up interviews were given to the interviewers. Most of the interviews were conducted in the participant's home or in institutional placement via computer-assisted interviewing in which a computer screen was visible to both the interviewer and participant. Participants were informed 
of the interviewers' obligation to maintain confidentiality. At each follow-up, sample retention was high (mean $=90 \%$ of the full sample). The procedures were reviewed and approved by the Institutional Review Boards of the participating universities. For complete details of the study methodology, see Mulvey (2004) and Schubert et al. (2004).

The present study focused on the 10 follow-up interviews over a period of 6.5 years. The total sample consisted of 11,965 person-observations of 1354 persons with a mean age of 18.9 years (standard deviation $(\mathrm{SD})=2.45$ ) ranging from 14 at the first follow-up point to 26 at the last time-point interview. If all the offenders in the Pathways to Desistance study had participated in all the assessment waves, a total of 13,540 person-observations would have been contributed, so $11.6 \%$ of all potential person-observations were missing. The sample was ethnically diverse, the majority $(40.1 \%)$ identified their ethnicity group as Black, $34.3 \%$ as Hispanic, and one fifth of the sample (20.9\%) as White. The remaining $4.7 \%$ of participants indicated multiple ethnicities.

\section{Measures}

\section{Psychopathic traits}

Psychopathic traits were measured via self-report using the Youth Psychopathic Traits Inventory (YPI; Andershed et al. 2002), which is a 50-item measure. The YPI assesses psychopathic traits on ten subscales, each containing five questions: Dishonest Charm, Grandiosity, Lying, Manipulation, Remorselessness, Callousness, Unemotionality, Impulsiveness, Irresponsibility, and Thrill Seeking. Respondents are asked to rate the degree to which the individual statements or items apply to them, using 4-point Likert-type scales $(1=$ does not apply at all; $2=$ does not apply well; 3 = applies fairly well; 4 = applies very well). The subscales map onto the three 
domains of psychopathy: affective (Callous-Unemotional; e.g., "I think that crying is a sign of weakness, even if no one sees you”), interpersonal (Grandiose-Manipulative; e.g., "I'm better than everyone at almost everything”), and behavioral (Impulsive-Irresponsible; e.g., "I have often been late to work or classes in school'). For simplicity, abbreviations 'CU', 'GM' and 'II' of the domains are used in this article. The correlations were calculated for the domains and found to be strong (range, $r=0.59-0.67, \mathrm{p}<0.001$ ). To minimize the influence of social desirability on responses, the YPI frames psychopathic traits as neutral or pleasing. The YPI was administered every 6 months for 2.5 years, and annually thereafter for 6.5 years. The internal consistency for the YPI total score and the domain scores was good (range, $\alpha=0.73-0.94$ ), and the intraclass correlation of the YPI scores $(\mathrm{ICC}=0.27)$ suggests that psychopathic traits were slightly stable over time.

\section{Romantic relationship quality and partner's antisocial influence}

The Quality of Romantic Relationships inventory (Pierce 1994; Pierce et al. 1997) measures a participant's subjective rating of his/her romantic relationship and is categorized into the level of quality. Romantic relationship quality reflects, for example, satisfaction, love, closeness and interpersonal support. In the current study, we assessed relationship quality using nine items: "How often is [Name] there for you when you need him/her?"; "In general, how happy are you with your relationship?”; “Compared to your friends' relationships, how good is yours?”; “How often do you wish you hadn't gotten into this relationship?"; "How is your relationship with [Name] compared to what you thought it would be?"; "How much do you love [Name]?"; "How many problems are there in your relationship?"; "If you used drugs, what would [Name]'s reaction be?"; "If you were involved in an illegal activity, what would [Name]'s reaction be?". 
For the first seven questions, the participant responded on a 5-point Likert scale and for the last two questions on a 4-point Likert scale. Scores of the items were summed into one continuous variable, with higher scores indicating a relationship of higher quality. In addition, a variable measuring a partner's antisocial influence, a subjective rating of the partner's suggestions regarding antisocial acts, was comprised of seven items all beginning with a phrase "Has [Main Romantic Partner] suggested...” followed by a question about antisocial behavior (e.g., “...that you should sell drugs/steal something/hit or beat someone up?"). It was based on a section of the Peer Delinquent Behavior measure (see "Peer Factors"), with high scores being undesirable, reflecting strong antisocial influence. The variables measuring romantic relationships were labeled as "Romantic relationship quality" and "Partner's antisocial influence" for the analyses. The internal consistency of the Quality of Romantic Relationships inventory was good at the follow-up time points (range, $\alpha=0.73-0.94$ ).

\section{Friendship quality and peer delinquency}

We used three dimensions to measure peer relationships: friendship quality, antisocial behavior and antisocial influence. The items on the Friendship Quality scale are adapted from the Quality of Relationships Inventory (Pierce 1994). In the Friendship Quality scale, participants are asked to average the rating across their five closest friends on a 4-point Likert scale ranging from "not at all" to "very much". Friendship quality reflects the respondent's subjective rating of closeness and support offered. It is composed of ten items (e.g., "How much can you count on the people for help with a problem?"; "How close do you think you will be to these people in 10 years?"). A mean of the ten items was computed for every participant with at least seven items containing valid data, higher scores indicating better quality. The measure was found to have good internal 
consistency at the follow-up time points (range, $\alpha=0.80-0.82$ ). The Peer Delinquent Behavior measure is a subset of items used by the Rochester Youth Study (Thornberry et al. 1994) to assess the degree of antisocial activity among a peer group. The measure has 12 items assessing antisocial behavior (e.g., "During the recall period, how many of your friends have sold drugs?") and seven antisocial influence items beginning with the phrase "During the recall period, how many of your friends have suggested...” followed by, for example, “...that you should sell drugs/steal something/hit or beat someone up?". Participants were asked to respond on a 5-point Likert scale $(1=$ none of them; $5=$ all of them). To build a variable reflecting peer delinquency, the dimensions of antisocial behavior and influence were summed so that lower scores were indicative of less delinquent behavior and less antisocial influence of peers. Cronbach's alphas ranged between 0.87 and 0.94 at the follow-up measures. The peer variables are called "Friendship quality" and "Peer delinquency" in this paper.

\section{Offending}

The Self-Report of Offending scale (SRO; Survey et al. 1991) was used to assess antisocial and illegal acts at each time point. The measure was coded dichotomously $(0=$ no acts; $1=$ at least one act) to indicate any or no offending (aggressive or income-based) in the recall period of 6 or 12 months.

\section{Demographics}

Gender, ethnicity and year of birth were used as time-invariant control variables in the current study. The year of birth was calculated by subtracting the age of the participant from the year of 
the baseline interview. Interview information was recorded as part of the data collection process for each study wave. Accordingly, interview location $(1=$ jail or detention; $0=$ other $)$ was used as a covariate to indicate the living facility during the recall period, and to control for the accessibility of interpersonal connections. In addition, we included a dichotomized measure for romantic relationships $(0=$ no relationship; $1=$ has/had a relationship during the recall period $)$. This covariate was only included in the analyses with peer variables.

\section{Statistical Analysis}

The cross-sectional time-series data of the Pathways to Desistance project enabled us to utilize within-individual analyses to detect the effects of interpersonal relationships on psychopathy. Data analyses were performed using Stata, version 13.1 (Stata Corp. LP, College Station, Texas, USA) statistical software. First, descriptive statistics, mean scores and pairwise correlation coefficients for independent and dependent variables were calculated. The person-observations were gathered from ten data waves and pooled into a single dataset $(n=11,965$ personobservations of 1354 persons). Second, in multilevel regression analyses (xtreg packages), we concentrated on the level 1 fixed-effects regressions to ensure that unobserved characteristics of the individuals were taken into account and biased variation was removed (see Curran and Bauer 2011). This within-individual analysis shows individual growth rates and variation around the individual's mean level of the exposure across all person-observations and can be expressed as a linear function of time: $\mathrm{yti}=\beta 0 \mathrm{i}+\beta$ 1i $\mathrm{xti}+\mathrm{r}$ ti , where $\beta$ 0i represents the intercept and $\beta$ 1i the linear slope for the ith individual, $x$ ti refers to the observed value of time at a follow-up measure point $\mathrm{t}$ for individual $\mathrm{i}$, and $\mathrm{r}$ ti indicates the time-specific and individual-specific residual. In cases where the within-individual association was statistically nonsignificant but the 
corresponding between-individual association significant, the difference between these coefficients was tested via the Wald test (Carlin et al. 2005).

For multilevel regressions, analyses for the romantic relationship and peer variables were conducted separately, and these time-varying independent variables were concurrently assessed at each study wave with the psychopathy inventory (models 1 and 2). Similar analyses were also calculated for psychopathy's three sub-domains. Regarding romantic relationship quality, the respondent had to be in a relationship during the recall period to be included in the analyses. An interaction term for gender was also computed (models 3 and 4 ) and if the interaction coefficient was statistically significant, differences between genders were tested through a null hypothesis $\mathrm{H}$ $o: \beta f=\beta \mathrm{m}$, where $\beta \mathrm{f}$ is the regression coefficient for females and $\beta \mathrm{m}$ for males. Moreover, the independent variables were lagged to the previously reported measurement time compared with the dependent variable (models 5 and 6) to emphasize the causal effects (i.e., variables measured one study wave before the psychopathy measure, rather than concurrently with the outcome). To control for the previous YPI scores, inclusion of a backward-lagged dependent variable was conducted (models 7 and 8). Finally, the impact of peer delinquency on the associations of romantic relationships and psychopathy was tested to exclude a possible mediation effect (model 9). In order to examine causes and effects more precisely, the associations were tested in reverse, so that the backward-lagged YPI was made an independent variable and interpersonal relationships as dependents. In all of the multilevel regression analyses, some covariates were adjusted for: gender, ethnicity, year of birth or age, relationship status (yes/no; included only in the peer analyses), self-reported offending (yes/no), study wave and interview location (jail or detention center / other). Gender, ethnicity and year of birth were time-invariant, and the rest were time-varying-variables. After calculating descriptive statistics, 
correlations and multilevel regressions, four groups of all person-observations were created by splitting the scores into four groups of exactly the same size based on the romantic relationship quality $(1=$ low quality; 2 = moderately low quality; $3=$ moderately high quality; $4=$ high quality). Those having no romantic relationship were designated as a fifth group. With analysisof-variance (ANOVA), we estimated whether or not the means of the psychopathic traits were equal among the five groups.

\section{Results}

\section{Descriptive Statistics}

Table 1 shows the descriptive statistics for all variables included in our analyses. More than half of the participants reported committing a crime at some point during the follow-up and about one-quarter had been interviewed in a jail or detention center at least once. Moreover, $55 \%$ of the sample declared they were in a romantic relationship. The YPI total score ranged between 21 and 197 , with a mean score of 102.85 ( $\mathrm{SD}=23.42)$. The mean for romantic relationship quality was $7.38(\mathrm{SD}=1.19 ;$ range $1-8)$ and for partner's antisocial influence $1.25(\mathrm{SD}=0.74$; range $1-8)$. Regarding peer factors, the mean score was $3.32(\mathrm{SD}=0.50$; range $1-4)$ for the friendship quality variable, and 4.31 ( $\mathrm{SD}=2.77$; range $1-9$ ) for peer delinquency with lower scores demonstrating less delinquency. The SDs for within-individual associations were lower than for the between-person associations in all the variables expressing interpersonal relationships.

Table 1 
Pairwise correlations between covariates, romantic relationship variables, peer factors and psychopathy total scores are reported in Table 1. Psychopathic traits (i.e., YPI total scores) were significantly associated with romantic relationship quality $(r=-0.18, p<0.001)$, partner's antisocial influence $(r=0.15, \mathrm{p}<0.001)$, friendship quality $(\mathrm{r}=-0.16, \mathrm{p}<0.001)$, and peer delinquency $(r=0.38, p<0.001)$. These correlations can be classified as low except for peer delinquency with a value reflecting a moderate correlation. A positive correlation for psychopathic traits was found with the dichotomous self-reported offending with a modest coefficient $(r=0.29, p<0.001)$. Neither age nor gender were significantly related to the quality of romantic relationships, although gender and partner's antisocial influence showed a low positive correlation $(\mathrm{r}=0.08, \mathrm{p}<0.001)$, indicating that females experience more antisocial influence from their partners than males. In contrast, compared to men, females report less delinquency among their peers and more friendships of quality. Being in a romantic relationship was more common among men than women, and males committed more offenses than females, according to the correlation matrix (Table 1).

\section{Association between Interpersonal Relationships and Psychopathic Traits}

In terms of within-individual changes conducted via multilevel regression analyses, the results of the influence of interpersonal relationships on psychopathy are provided in Fig. 1 and Table 1. Both the quality of romantic relationships and the friendship quality had main effects on psychopathic traits $(\mathrm{p}<0.001)$ after controlling for age, gender, ethnicity, relationship status (in the peer analyses), self-reported offending, study wave and interview location (models 1 and 2), indicating that high-quality interpersonal relationships were associated with lower psychopathic traits in the within-individual regressions. Partner's antisocial influence and peer delinquency, in 
contrast, increased the level of psychopathic traits $(\mathrm{p}<0.001)$. In addition, the quality of romantic relationships and partner's antisocial influence were associated with psychopathy's sub-domains: CU, GM and II (see Appendix Table 4 for numerical details). The only exception was the within-individual association between friendship quality and II, which indicated statistical non-significance $(\mathrm{p}=0.49$ ), while the corresponding between-individual coefficient was significant $(\mathrm{p}<0.001)$.

Fig. 1

Next, multilevel regressions were conducted including either the interaction term of gender and romantic relationship factors or gender and peer factors (models 3 and 4). Table 3 shows the regression coefficients for within-individual variations separately for males and females. In general, the associations between interpersonal variables and psychopathy were stronger for females, but the interaction for gender was only statistically significant for peer delinquency $(\mathrm{p}<0.001)$. The between-individual interaction terms produced equivalent results in terms of statistical significance. The within-individual associations between backward-lagged romantic relationship variables and psychopathy were not statistically significant $(p=0.097$; $\mathrm{p}=0.150$ ), nevertheless, in between-individual analyses, the associations showed significance $(\mathrm{p}<0.001)$. The differences for the within-individual and between-individual regression coefficients demonstrated significance (Wald test, $\mathrm{p}<0.001$ ), reflecting that romantic relationships could not predict psychopathic traits across a recall period of 6-12 months at an 
individual level. The results of the peer variable models remained unchanged when explanatory factors were used in a backward-lagged fashion (model 6) (Tables 2, 3). Inclusion of backwardlagged psychopathy as a covariate weakened the associations slightly without invalidating the statistical significance and similarly, peer delinquency did not change the effect of romantic relationship quality or partner's antisocial influence on psychopathic traits (models 7-9). Regarding causality in reverse, the backward-lagged psychopathy scores did not predict interpersonal relationships at a statistically significant level, except for peer delinquency $(\mathrm{p}<0.001)$.

Table 2

Table 3

\section{Analysis for Romantic Relationship Groups}

The higher the self-rated quality of a romantic relationship, the lower the respondent scored on the psychopathic measure, on average (Fig. 2). Importantly, those having no romantic relationship had lower mean levels of psychopathic traits $(\mathrm{M}=103.56, \mathrm{SD}=23.09)$ than those rating their relationship quality as low $(M=108.34, S D=23.12)$ or moderately low $(M=104.15$, $\mathrm{SD}=22.74)$. The lowest mean levels of psychopathic traits were seen from those classifying their romantic relationship quality as high $(\mathrm{M}=96.62, \mathrm{SD}=23.59$. The ANOVA showed significant differences between the groups, yielding an $\mathrm{F}$ ratio of $\mathrm{F}(4,11,947)=61.29, \mathrm{p}<0.001$. 
Fig. 2

\section{Discussion}

Studies investigating protective factors against psychopathy in adolescence with appropriate methods are scarce. Close and meaningful connection with peers is one of the strongest indicators of psychological wellbeing in adolescence, and the quality of peer relationships influences adolescent's self-concept, identity and behavior (Hall-Lande et al. 2007). A few studies have found that interpersonal relationships may act as protection for delinquency (RhuleLouie and McMahon 2007; Shepherd et al. 2016; Zedaker and Bouffard 2017) or psychopathy (Barry et al. 2008; Fanti et al. 2017; Muñoz et al. 2008). Quality of peer and romantic relationships has been overlooked in previous studies in adolescents. The current study examined whether interpersonal relationships predict the level of psychopathic traits and its sub-domains among offending adolescents over a 6.5-year period. Both romantic partners and peers can have protective and harmful associations with psychopathic traits, depending on the relationship quality (based on satisfaction, closeness and supportiveness) and level of antisocial behavior and influence. These associations were observed in a within-individual analysis of ten repeated measurements, providing evidence of a potentially causal association between interpersonal relationships and psychopathic traits.

On a scale of low to high, the quality of both romantic relationships and friendships associated negatively with psychopathic traits, regardless of age, gender, ethnicity, self-reported 
offending and living facilities. We focused on the relationship quality instead of the relationship status because quality has been overlooked in previous studies (e.g., Rhule-Louie and McMahon 2007; Zedaker and Bouffard 2017). We found that psychopathic traits were the lowest among those with romantic relationships of high quality, highest among those in the lowest quality intimate relationships, and in between for those not in a relationship. It could thus be argued that it is better not to have a romantic relationship than to have one of low quality. In other words, the quality matters more than the relationship status itself, which is in line with previous findings (Monahan et al. 2014; Wyse et al. 2014; Zedaker and Bouffard 2017; see also Rhule-Louie and McMahon 2007 for review). Also, with respect to friendships, these findings extend the previous work of peers' protective roles against psychopathic features (Barry et al. 2008; Muñoz et al. 2008) and disagree with studies stating that positive friendships cannot reduce psychopathic-like traits (Kokkinos et al. 2016; Pardini and Loeber 2008).

Also in agreement with our hypothesis, partner's antisocial influence and peer delinquency increased the risk for psychopathy, suggesting that the more antisocial activities the adolescent experiences in his/her interpersonal relationships, the higher he/she scores on psychopathic measures. These results support previous studies regarding peers (Lynam et al. 2008; Muñoz et al. 2008; Tatar et al. 2016) and romantic partners (Eklund et al. 2010; Haynie et al. 2005; Monahan et al. 2014; Simons et al. 2002). Although we investigated romantic and peer relationships separately, we also controlled for peer delinquency in the analyses measuring romantic relationships because it is said that other prosocial people may contribute to the association of romantic relationships (Haynie et al. 2005; Wright and Cullen 2004; Zedaker and Bouffards 2017). We found that romantic relationships contribute to psychopathic traits of adolescents even after peer delinquency was taken into account. 
Interpersonal relationships were similarly associated with all three of the sub-domains of psychopathy. This supports the previous suggestions of Barry et al. (2008), Salekin (2016), and Salihovic and Stattin (2016), who found that studying all of the domains of psychopathy constructs is important. Friendship quality did not influence the behavioral component of psychopathy in the within-individual analysis. This finding strengthens an earlier finding of impulsive individuals being less influenced by their relationships (Zedaker and Bouffard 2017).

Farrington et al. (2002), Hemphill et al. (2015) and Pardini and Loeber (2008) found that antisocial peers are a risk factor for antisocial behavior only in predicting differences between individuals but not within the same individual across time. We discovered, however, that peer delinquency also associated with the behavioral domain within individuals, demonstrating that changes in peer delinquency can produce changes in psychopathic traits at an individual level across time. Reasons for these discrepant findings may stem from the operationalization of the variables; our study included both antisocial behavior and antisocial influence of peers, whereas the previous studies concentrated only on antisocial behavior. In addition, our findings disagree with studies suggesting that prosocial peers show no effect on CU traits (Kokkinos et al. 2016; Pardini and Loeber 2008), since we noted a protective effect of friendship quality on psychopathic traits, including the affective domain reflecting CU traits. However, it is noteworthy that prosocial influence may not necessarily be identical to a high-quality friendship, which makes the studies partially incomparable.

Past research has indicated that the association between romantic relationships and delinquency may be different between males and females (e.g., Monahan et al. 2014; RhuleLouie and McMahon 2007). Compared to their male counterparts, our results show that affiliating with delinquent friends intensifies psychopathic traits more among females. A similar, 
although not significant, trend was seen for partner's antisocial influence and for interpersonal relationship quality among females. Thus, females are more apt to be affected by interpersonal relationships, as also reported in previous studies (Eklund et al. 2010; Haynie et al. 2005; Kerig 2014). This issue requires further investigation.

Our results suggest that romantic relationships associate with psychopathy only in the short-term because the backward-lagged variables of romantic relationships had no withinindividual effects on psychopathic traits. It is worth noting that the reports of participants included their experiences of intimate relationships retrospectively over the entire recall period of 6-12 months, regardless of their current relationship status. The psychopathy measure used asks the participant to rate the items with a general impression without concentrating on a specific recall period. In addition, we controlled for the previous psychopathic scores in order to stress the latest levels and remove the chance for reverse causal effects. The results remained significant and indicated that romantic relationships influence psychopathic traits immediately. These findings are thereby in line with Larson et al. (2016), who speculated that the effects of adolescents' romantic relationships and breakups are relatively acute. In contrast, friendship quality and peer delinquency appeared to have acute as well as longer term influence on psychopathic traits, possibly up to 12-24 months, depending on the length of the recall period.

The underlying mechanisms of the capacity for high-quality relationships to protect against psychopathy are unknown. The mechanisms may be similar to those proposed for romantic relationships and desistance from delinquency, such as a strong bond to the partner (Haynie et al. 2005; Zedaker and Bouffard 2017) or social support (Sampson et al. 2006; Wyse et al. 2014). It is also worth noting that a potential third factor, such as motivation to change (Salekin et al. 2010), attachment, subjective well-being (Love and Holder 2016) or genetic 
predisposition to attract high-quality partners (Beaver et al. 2008) are important to consider. Moreover, the issue of temperament, particularly the distinction between primary and secondary psychopathy (see Skeem et al. 2003), may also be relevant. For example, Savard et al. (2006) found different effects of couple distress on primary and secondary psychopaths, as did Ali and Chamorro-Premuzic (2010) in terms of intimacy. Hall and Benning (2006) propose that the manifestation of psychopathy depends on the intervening variables that moderate the temperamental base. Protective factors may thus inhibit psychopathic-like behavior and attenuate the expression of the psychopathic disorder (Mahmut et al. 2008), or perhaps they positively increase the experience of emotions (Keulen-de Vos et al. 2017) or social skills (Caldwell et al. 2012). Possible alterations in neurobiology due to high-quality relationships are worth studying, because adolescence is a time for rapid and complex changes in the brain and behavior (Colver and Longwell 2013). Based on our study, it remains unclear whether high-quality interpersonal relationships are able to change the underlying psychopathic temperament or solely attenuate the manifestation of psychopathic traits. In short, it remains ambiguous through which mechanisms the protective effect is achieved and whether the effect is similar to those with primary and secondary psychopathy.

The present study has several strengths. We analyzed interpersonal relationships and psychopathic traits among seriously delinquent adolescents with a longitudinal dataset in which the offending adolescents were observed for a period of 6.5 years. From a statistical perspective, analyses were conducted using within-individual methods to shed light on the causal trajectories of interpersonal relationships on psychopathy. Taking the viewpoint of protection against psychopathy was justified because empirical support for this postulation is limited. We also investigated the associations broadly with both romantic relationships and friendships, including 
the quality as well as the antisocial aspects of these relationships. Psychopathy's three domains and gender differences were taken into consideration.

The findings of our study, however, must also be understood within the context of its limitations. First, the dataset comprises serious offending adolescents. Generalizing these results to less delinquent samples should be done with caution. Second, we had to rely solely upon selfreports for measuring psychopathy, quality of interpersonal relationships, antisocial activities of partners and peers, and all of the covariates. The suggestion that psychopaths tend to misinterpret the quality of their relationships (Muñoz et al. 2008) is noteworthy in this context, thus, replicating these results with methods other than self-reports are needed. Finally, marital and dating relationships should be differentiated in future studies, since they may have different impacts (Larson et al. 2016).

In terms of prevention, there is evidence that traits associated with psychopathy are amenable to appropriate treatment in adolescence (Reidy et al. 2015). For example, the Mendota Juvenile Treatment Center (MJTC) is a correctional facility designed to provide mental health treatment and improvement in interpersonal functioning and behavioral control to juvenile offenders (Caldwell et al. 2012). Teaching adolescents to favor healthier relationships with prosocial individuals and employing positive reinforcement of prosocial relationships may reduce psychopathic traits (see Reidy et al. 2015). Easy access or inexpensive services to improve romantic relationship satisfaction should be provided to adolescents. Moreover, interpersonal relationships should be taken into account in treatment and intervention programs targeted to psychopathic individuals or offending adolescents. Reducing affiliations with delinquent peers and partners may prove beneficial for both adolescents with elevated psychopathic traits and the individuals involved with them. With offending adolescents, careful 
consideration of detention facilities and the effects of imprisonment are salient points because isolating an adolescent from his or her high-quality interpersonal relationships may hamper positive socialization (see Salekin et al. 2010).

\section{Conclusion}

In many previous studies among adolescents, the focal point of interest has been in the risks for developing psychopathy rather than in factors promoting a positive outcome. In this study, we considered both protective and risk factors by examining quality of relationships and their antisocial nature in adolescent offenders. We also examined gender differences because some studies have found males to be more resistant to a partner's antisocial influence than females (e.g. Kerig 2014; Rhule-Louie and McMahon 2007). Importantly, the causes of psychopathy were analyzed through intra-individual changes over time because the method adjusts for all the time-invariant confounding factors that may create spurious correlations. Peer and romantic relationships of high quality were associated with lower psychopathic traits whereas antisocial behavior and antisocial influence in relationships were related to higher psychopathic traits. Delinquent peers intensified psychopathic features more among females than males. We also found that those who do not have a romantic relationship had lower mean levels of psychopathic traits than those having a relationship of low quality.

This study shows that being satisfied in a romantic relationship and, accordingly, considering this relationship to be of high quality in terms of the amount of love, closeness and interpersonal support, may protect adolescents and young adults from psychopathy. Protection against psychopathy may also be achieved by adolescents' high-quality friendships, in terms of 
closeness to and support from peers. On the other hand, we also found that partner's antisocial influence (i.e., subjective rating of partner's suggestions regarding antisocial acts) and peer delinquency, reflecting antisocial activity among one's peer group have a tendency to increase psychopathic traits among youth. The findings suggest that in adolescence, peers and romantic partners can act either as protective or risk factors on psychopathic features, depending on the quality and antisocial activities of the relationships.

\section{Appendix}

Table 4 


\section{References}

Ali, F., \& Chamorro-Premuzic, T. (2010). The dark side of love and life satisfaction: Associations with intimate relationships, psychopathy and machiavellianism. Personality and Individual Differences, 48(2), 228-233.

Andershed, H. A., Kerr, M., Stattin, H., \& Levander, S. (2002). Psychopathic traits in non-referred youths: a new assessment tool. In E. Blaauw, L. Sheridan (Eds.), Psychopaths: current international perspectives (pp. 131-158). Den Haag: Elsevier.

Barry, T. D., Barry, C. T., Deming, A. M., \& Lochman, J. E. (2008). Stability of psychopathic characteristics in childhood the influence of social relationships. Criminal Justice and Behavior, 35 (2), 244-262.

Beaver, K. M., Wright, J. P., DeLisi, M., \& Vaughn, M. G. (2008). Desistance from delinquency: The marriage effect revisited and extended. Social Science Research, 37(3), 736-752.

Bergstrøm, H., Forth, A. E., \& Farrington, D. P. (2016). The psychopath: continuity or change? In A. Kapardis, D. P. Farrington (Eds.), The Psychology of Crime, Policing and Courts (pp. 94-116). London and New York: Routledge.

Blair, R. J. R. (2013). The neurobiology of psychopathic traits in youths. Nature reviews. Neuroscience, 14(11), 786-799.

Caldwell, M. F., McCormick, D., Wolfe, J., \& Umstead, D. (2012). Treatment-related changes in psychopathy features and behavior in adolescent offenders. Criminal Justice and Behavior, 39(2), 144-155. 
Capaldi, D., DeGarmo, D., Patterson, G. R., \& Forgatch, M. (2002).

Contextual risk across the early life span and association with antisocial behavior. In J. B. Reid, G. R. Patterson, \& J. Snyder (Eds.), Antisocial behavior in children and adolescents: A developmental analysis and model for intervention (pp.

123-145). http://dx.doi.org/10.1037/10468-000.

Carlin, J. B., Gurrin, L. C., Sterne, J. A., Morley, R., \& Dwyer, T. (2005). Regression models for twin studies: A critical review. International Journal of Epidemiology, 34(5), 1089-1099.

Cleckley, H. M. (2016). The mask of sanity: An attempt to clarify some issues about the so-called psychopathic personality. 3rd edn., Pickle Partners Publishing. http://books.google.com

Colver, A., \& Longwell, S. (2013). New understanding of adolescent brain development: relevance to transitional healthcare for young people with long term conditions. Archives of disease in childhood, 98(11), 902-907.

Curran, P. J., \& Bauer, D. J. (2011). The disaggregation of withinperson and between-person effects in longitudinal models of change. Annual Review of Psychology, 62, 583-619.

DeLisi, M. (2009). Psychopathy is the unified theory of crime. Youth Violence and Juvenile Justice, 7(3), 256-273.

DeMatteo, D., Heilbrun, K., \& Marczyk, G. (2005). Psychopathy, risk of violence, and protective factors in a noninstitutionalized and noncriminal sample. International Journal of Forensic Mental Health, 4(2), 147-157. 
Eklund, J. M., Kerr, M., \& Stattin, H. (2010). Romantic relationships and delinquent behaviour in adolescence: The moderating role of delinquency propensity. Journal of Adolescence, 33(3), 377-386.

Fanti, K. A. (2013). Individual, social, and behavioral factors associated with co-occurring conduct problems and callousunemotional traits. Journal of Abnormal Child Psychology, 41 (5), 811-824.

Fanti, K. A., Colins, O. F., Andershed, H., \& Sikki, M. (2017). Stability and change in callous-unemotional traits: Longitudinal associations with potential individual and contextual risk and protective factors. American Journal of Orthopsychiatry, 87(1), 62.

Farrington, D. P. (1986). Age and crime. Crime and Justice, 7, 189-250.

Farrington, D. P., Loeber, R., Yin, Y., \& Anderson, S. J. (2002). Are within-individual causes of delinquency the same as betweenindividual causes? Criminal Behaviour and Mental Health, 12(1), 53-68.

Frick, P. J. (2009). Extending the construct of psychopathy to youth: Implications for understanding, diagnosing, and treating antisocial children and adolescents. The Canadian Journal of Psychiatry, 54(12), 803-812.

Frick, P. J., Kimonis, E. R., Dandreaux, D. M., \& Farell, J. M. (2003). The 4 year stability of psychopathic traits in non-referred youth. Behavioral Sciences \& the Law, 21(6), 713-736.

Frick, P. J., Ray, J. V., Thornton, L. C., \& Kahn, R. E. (2014). Annual research review: A developmental psychopathology approach to 
understanding callous-unemotional traits in children and adolescents

with serious conduct problems. Journal of Child Psychology

and Psychiatry, 55(6), 532-548.

Hall, J. R., \& Benning, S. D. (2006). The "successful" psychopath.

In C. J. Patrick (Ed.), Handbook of psychopathy (pp. 459-478).

New York: Guilford Press.

Hall-Lande, J. A., Eisenberg, M. E., Christenson, S. L., \& Neumark-

Sztainer, D. (2007). Social isolation, psychological health, and

protective factors in adolescence. Adolescence, 42(166), 265.

Hare, R. D. (2003). The psychopathy checklist-Revised. Toronto, ON.

http://books.google.com

Hawes, S. W., Mulvey, E. P., Schubert, C. A., \& Pardini, D. A. (2014).

Structural coherence and temporal stability of psychopathic personality features during emerging adulthood. Journal of Abnormal

Psychology, 123(3), 623.

Haynie, D. L., Giordano, P. C., Manning, W. D., \& Longmore, M. A. (2005). Adolescent romantic relationships and delinquency involvement. Criminology, 43(1), 177-210.

Hemphill, S. A., Heerde, J. A., Herrenkohl, T. I., \& Farrington, D. P. (2015). Within-individual versus between-individual predictors of antisocial behaviour: A longitudinal study of young people in victoria, australia. Australian \& New Zealand Journal of Criminology, 48(3), 429-445.

Jonason, P. K., Luevano, V. X., \& Adams, H. M. (2012). How the dark triad traits predict relationship choices. Personality and Individual Differences, 53(3), 180-184. 
Kerig, P. K. (2014). Introduction: For better or worse: Intimate relationships as sources of risk or resilience for girls' delinquency.

Journal of Research on Adolescence, 24(1), 1-11.

Kerr, M., Van Zalk, M., \& Stattin, H. (2012). Psychopathic traits moderate peer influence on adolescent delinquency. Journal of Child Psychology and Psychiatry, 53(8), 826-835.

Keulen-de Vos, M., van den Broek, E. P. A., Bernstein, D. P., Vallentin, R., \& Arntz, A. (2017). Evoking emotional states in personality disordered offenders: An experimental pilot study of experiential drama therapy techniques. The Arts in Psychotherapy,

$53,80-88$.

Kimonis, E. R., Frick, P. J., \& Barry, C. T. (2004). Callousunemotional traits and delinquent peer affiliation. Journal of Consulting and Clinical Psychology, 72(6), 956.

Kokkinos, C. M., Voulgaridou, I., \& Markos, A. (2016). Personality and relational aggression: Moral disengagement and friendship quality as mediators. Personality and Individual Differences, 95, 74-79.

Larson, M., Sweeten, G., \& Piquero, A. R. (2016). With or without you? contextualizing the impact of romantic relationship breakup on crime among serious adolescent offenders. Journal of Youth and Adolescence, 45(1), 54-72.

Love, A. B., \& Holder, M. D. (2014). Psychopathy and subjective well-being. Personality and Individual Differences, 66, 112-117.

Love, A. B., \& Holder, M. D. (2016). Can romantic relationship quality mediate the relation between psychopathy and subjective 
well-being? Journal of Happiness Studies, 17(6), 2407-2429.

Lynam, D. R., Caspi, A., Moffitt, T. E., Loeber, R., \& Stouthamer-

Loeber, M. (2007). Longitudinal evidence that psychopathy

scores in early adolescence predict adult psychopathy. Journal of

Abnormal Psychology, 116(1), 155.

Lynam, D. R., \& Gudonis, L. (2005). The development of psychopathy.

Annu.Rev.Clin.Psychol., 1, 381-407.

Lynam, D. R., Loeber, R., \& Stouthamer-Loeber, M. (2008). The

stability of psychopathy from adolescence into adulthood: The

search for moderators. Criminal Justice and Behavior, 35(2),

$228-243$.

Mahmut, M. K., Homewood, J., \& Stevenson, R. J. (2008). The

characteristics of non-criminals with high psychopathy traits: Are

they similar to criminal psychopaths? Journal of Research in

Personality, 42(3), 679-692.

Maume, M. O., Ousey, G. C., \& Beaver, K. (2005). Cutting the grass:

A reexamination of the link between marital attachment, delinquent

peers and desistance from marijuana use. Journal of

Quantitative Criminology, 21(1), 27-53.

Moffitt, T. E. (1993). Adolescence-limited and life-course-persistent

antisocial behavior: A developmental taxonomy. Psychological

Review, 100(4), 674.

Moffitt, T. E., Caspi, A., Harrington, H., \& Milne, B. J. (2002). Males

on the life-course-persistent and adolescence-limited antisocial

pathways: Follow-up at age 26 years. Development and Psychopathology,

14(01), 179-207. 
Monahan, K. C., Dmitrieva, J., \& Cauffman, E. (2014). Bad romance:

Sex differences in the longitudinal association between romantic

relationships and deviant behavior. Journal of Research on

Adolescence, 24(1), 12-26.

Mulvey, E. P. (2004). Introduction: Pathways to desistance study.

Youth Violence and Juvenile Justice, 2(3), 211-212.

Muñoz, L. C., Kerr, M., \& Bsic, N. (2008). A matter of perspective:

The peer relationships of youths with psychopathic personality

traits. Criminal Justice and Behavior, 35, 212-227.

Pardini, D. A., \& Loeber, R. (2008). Interpersonal callousness trajectories across adolescence: Early social influences and adult

outcomes. Criminal Justice and Behavior, 35(2), 173-196.

Pierce, G. R. (1994). The quality of relationships inventory: Assessing the interpersonal context of social support.

Pierce, G. R., Sarason, I. G., Sarason, B. R., Solky-Butzel, J. A., \&

Nagle, L. C. (1997). Assessing the quality of personal relationships. Journal of Social and Personal Relationships, 14(3),

339-356.

Ray, J. V., Frick, P. J., Thornton, L. C., Wall Myers, T. D., Steinberg, L., \& Cauffman, E. (2017). Callous-unemotional traits predict self-reported offending in adolescent boys: The mediating role of delinquent peers and the moderating role of parenting practices. Developmental Psychology, 53(2), 319.

Reidy, D. E., Kearns, M. C., DeGue, S., Lilienfeld, S. O., Massetti, G., \& Kiehl, K. A. (2015). Why psychopathy matters: Implications 
for public health and violence prevention. Aggression and Violent Behavior, 24, 214-225.

Rhule-Louie, D. M., \& McMahon, R. J. (2007). Problem behavior and romantic relationships: Assortative mating, behavior contagion, and desistance. Clinical Child and Family Psychology Review, 10 (1), 53-100.

Rubio, J. S., Krieger, M. A., Finney, E. J., \& Coker, K. L. (2014). A review of the relationship between sociocultural factors and juvenile psychopathy. Aggression and Violent Behavior, 19(1), $23-31$.

Salekin, R. T. (2008). Psychopathy and recidivism from midadolescence to young adulthood: Cumulating legal problems and limiting life opportunities. Journal of Abnormal Psychology, $117(2), 386$.

Salekin, R. T. (2016). Psychopathy in childhood: Why should we care about grandiose-manipulative and daring-impulsive traits? The British Journal of Psychiatry, 209(3), 189-191.

Salekin, R. T., \& Lochman, J. E. (2008). Child and adolescent psychopathy: The search for protective factors. Criminal Justice and Behavior, 35(2), 159-172.

Salekin, R. T., Worley, C., \& Grimes, R. D. (2010). Treatment of psychopathy: A review and brief introduction to the mental model mpproach for psychopathy. Behavioral Sciences \& the Law, 28 (2), 235-266.

Salihovic, S., \& Stattin, H. (2016). Psychopathic traits and delinquency trajectories in adolescence. Journal of Psychopathology 
and Behavioral Assessment, 39(1), 15-24.

Sampson, R. J., \& Laub, J. H. (1995). Crime in the making: Pathways and turning points through life. Harvard University Press. http:// books.google.com

Sampson, R. J., Laub, J. H., \& Wimer, C. (2006). Does marriage reduce crime? A counterfactual approach to within-individual causal effects. Criminology, 44(3), 465-508.

Savard, C., Sabourin, S., \& Lussier, Y. (2006). Male sub-threshold psychopathic traits and couple distress. Personality and Individual Differences, 40(5), 931-942.

Schimmenti, A., Passanisi, A., Pace, U., Manzella, S., Di Carlo, G., \& Caretti, V. (2014). The relationship between attachment and psychopathy: A study with a sample of violent offenders. Current Psychology, 33(3), 256-270.

Schubert, C. A., Mulvey, E. P., Steinberg, L., Cauffman, E., Losoya, S. H., \& Hecker, T., et al. (2004). Operational lessons from the pathways to desistance project. Youth Violence and Juvenile Justice, 2(3), 237-255.

Shepherd, S. M., Luebbers, S., \& Ogloff, J. R. (2016). The role of protective factors and the relationship with recidivism for highrisk young people in detention. Criminal Justice and Behavior, 43(7), 863-878.

Simons, R. L., Stewart, E., Gordon, L. C., Conger, R. D., \& Elder, G. H. (2002). A test of life-course explanations for stability and change in antisocial behavior from adolescence to young adulthood. Criminology, 40(2), 401-434. 
Skeem, J. L., Poythress, N., Edens, J. F., Lilienfeld, S. O., \& Cale, E. M. (2003). Psychopathic personality or personalities? Exploring potential variants of psychopathy and their implications for risk assessment. Aggression and Violent Behavior, 8(5), 513-546.

Survey, D. Y., Huizinga, D., Esbensen, F., \& Weiher, A. W. (1991). Are there multiple paths to delinquency? Journal of Criminal Law and Criminology, 82(1), 83-118.

Tatar, II, J. R., Cavanagh, C., \& Cauffman, E. (2016). The importance of (anti) social influence in serious juvenile offenders with psychopathic traits. Psychology, Public Policy, and Law, 22(1), 92.

Thornberry, T. P., Lizotte, A. J., Krohn, M. D., Farnworth, M., \& Jang, S. J. (1994). Delinquent peers, beliefs, and delinquent behavior: A longitudinal test of interactional theory. Criminology, 32, 47-83.

Thornton, L. C., Frick, P. J., Shulman, E. P., Ray, J. V., Steinberg, L., \& Cauffman, E. (2015). Callous-unemotional traits and adolescents' role in group crime. Law and Human Behavior, 39(4), 368.

Van Zalk, M. H. W., \& Van Zalk, N. (2015). Violent peer influence: The roles of self-esteem and psychopathic traits. Development and Psychopathology, 27(4pt1), 1077-1088.

Waller, R., Gardner, F., \& Hyde, L. W. (2013). What are the associations between parenting, callous-unemotional traits, and antisocial behavior in youth? A systematic review of evidence.

Clinical psychology review, 33(4), 593-608.

Warr, M. (1998). Life-course transitions and desistance from crime. 
Criminology, 36(2), 183-216.

Wright, J. P., \& Cullen, F. T. (2004). Employment, peers, and lifecourse transitions. Justice Quarterly, 21(1), 183-205.

Wyse, J. J., Harding, D. J., \& Morenoff, J. D. (2014). Romantic

relationships and criminal desistance: Pathways and processes.

Sociological Forum, 29(2), 365-385.

Zedaker, S. B., \& Bouffard, L. A. (2017). Relationship status, romantic relationship quality, monitoring, and antisocial influence:

Is there an effect on subsequent offending? Journal of

Developmental and Life-Course Criminology, 3(1), 62-75.

Zimmer-Gembeck, M. J. (2002). The development of romantic relationships and adaptations in the system of peer relationships.

Journal of Adolescent Health, 31(6), 216-225. 

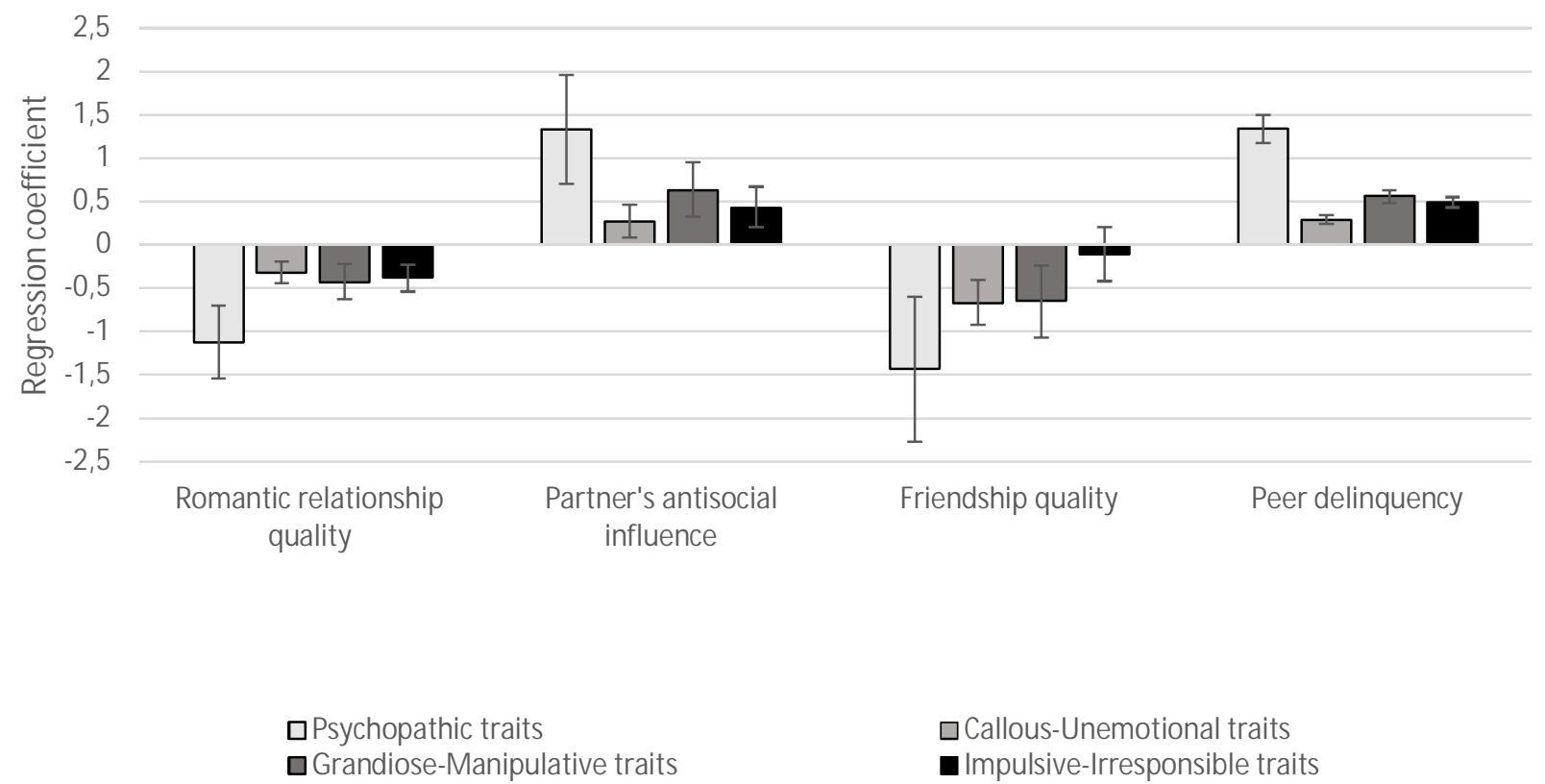

Fig. 1 Associations between interpersonal relationships and psychopathic traits for within-individual regressions. Bars represent the magnitude of linear regression coefficients. Error bars are 95\% confidence intervals N=up to 11,965 personobservations from 1354 individuals between years 2000 and 2010. Online Resource 1 for numerical details

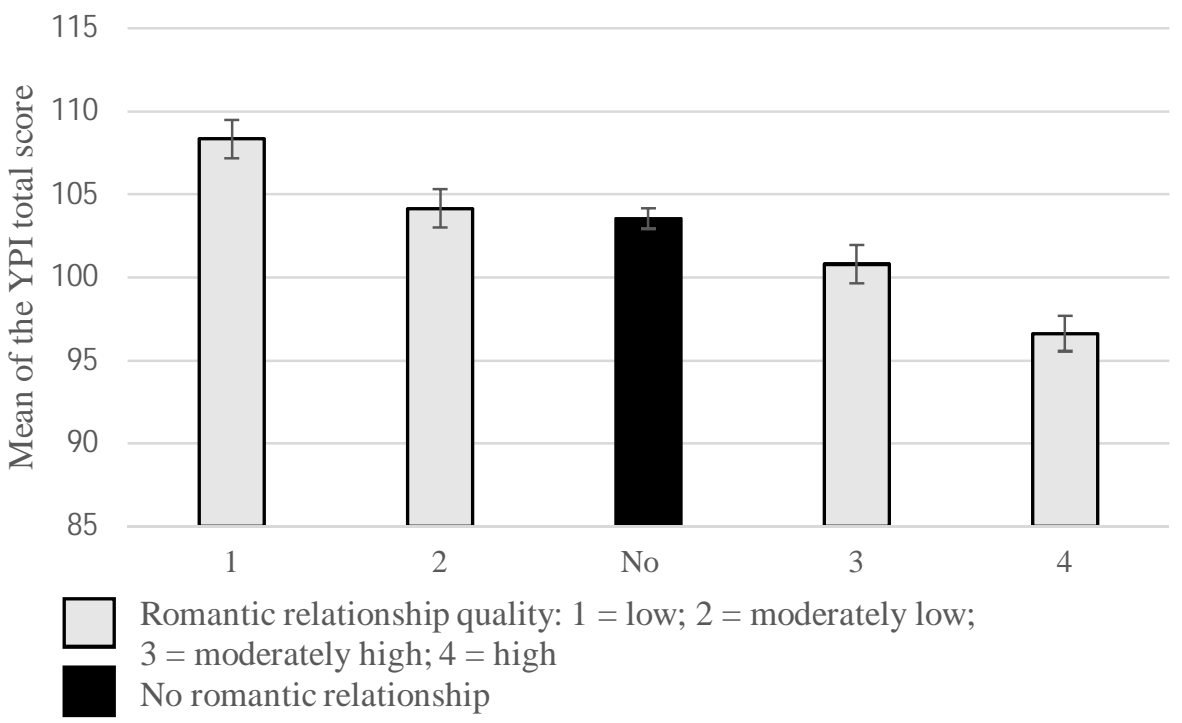

Fig. 2 Mean scores of psychopathic traits (YPI total score) among romantic relationship groups based on subjectively rated levels of relationship quality, and for those not having a romantic relationship. Error bars are $95 \%$ confidence intervals. Mean differences statistically significant $F(4,11947)=61.29, p<0.001$ (ANOVA) 
Table 1 Descriptive statistics and Pearson correlations (columns labeled 2-11) of the covariates, independent variables and outcome variable for the 11,965 personobservations from 1354 individuals over the 10 data collection waves in the Pathways to Desistance study, 2000-2010

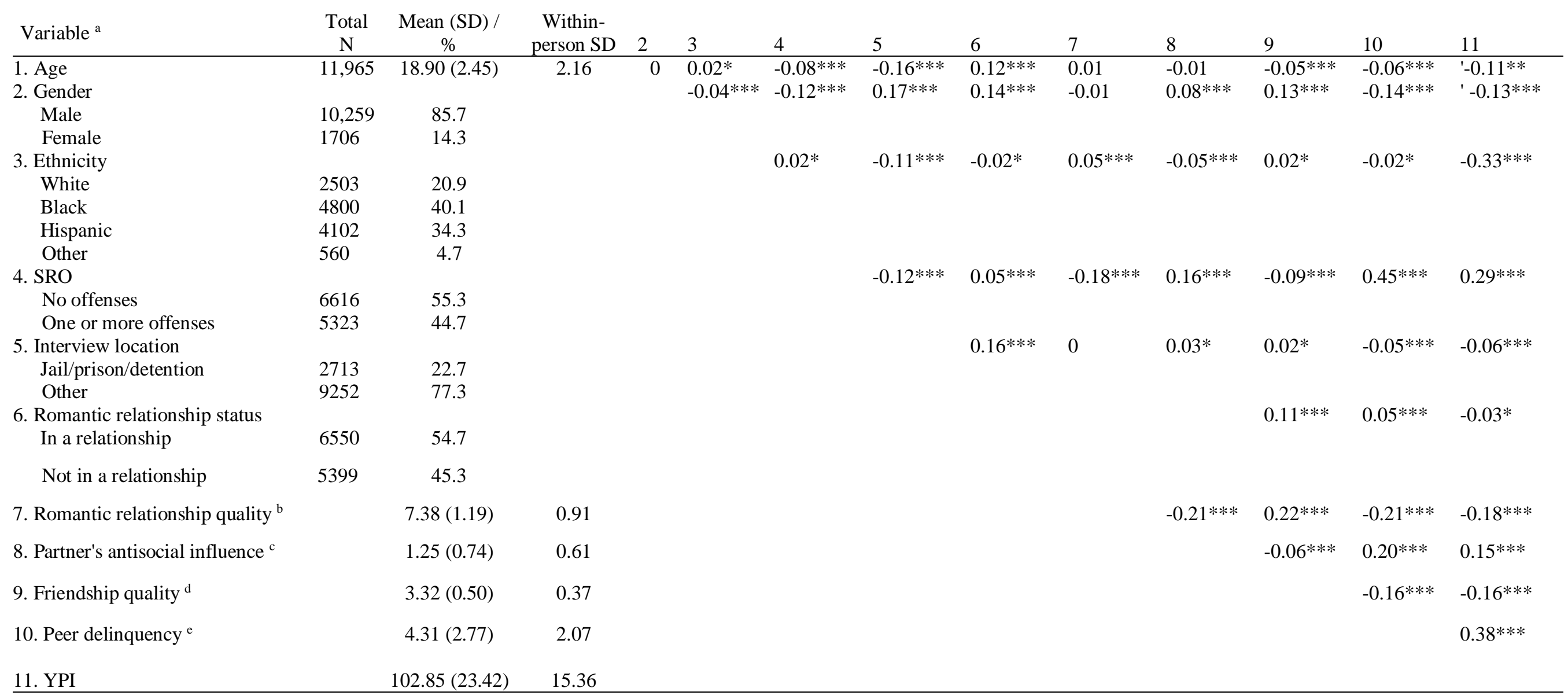

Abbreviations: SD = standard deviation; SRO = Self-Reported Offending; YPI = Youth Psychopathic Traits Inventory total score (range 50-197)

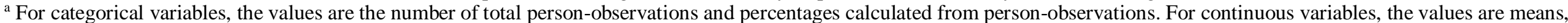

overall standard deviations, and within-individual standard deviations.

${ }^{\mathrm{b}}$ Range $1-8$ ( 1 = lowest; 8 = highest quality)

${ }^{\mathrm{c}}$ Range $1-8$ ( $1=$ least; $8=$ most antisocial influence)

${ }^{\mathrm{d}}$ Range 1-4 (1 = lowest; 4 = highest quality)

e Range 1-9 ( $1=$ least; $9=$ most antisocial behavior and influence $)$

$* \mathrm{p}<0.05 ; * * \mathrm{p}<0.01 ; * * \mathrm{p}<0.001$ 
Table 2 Regression coefficients of independent variables and covariates for psychopathy

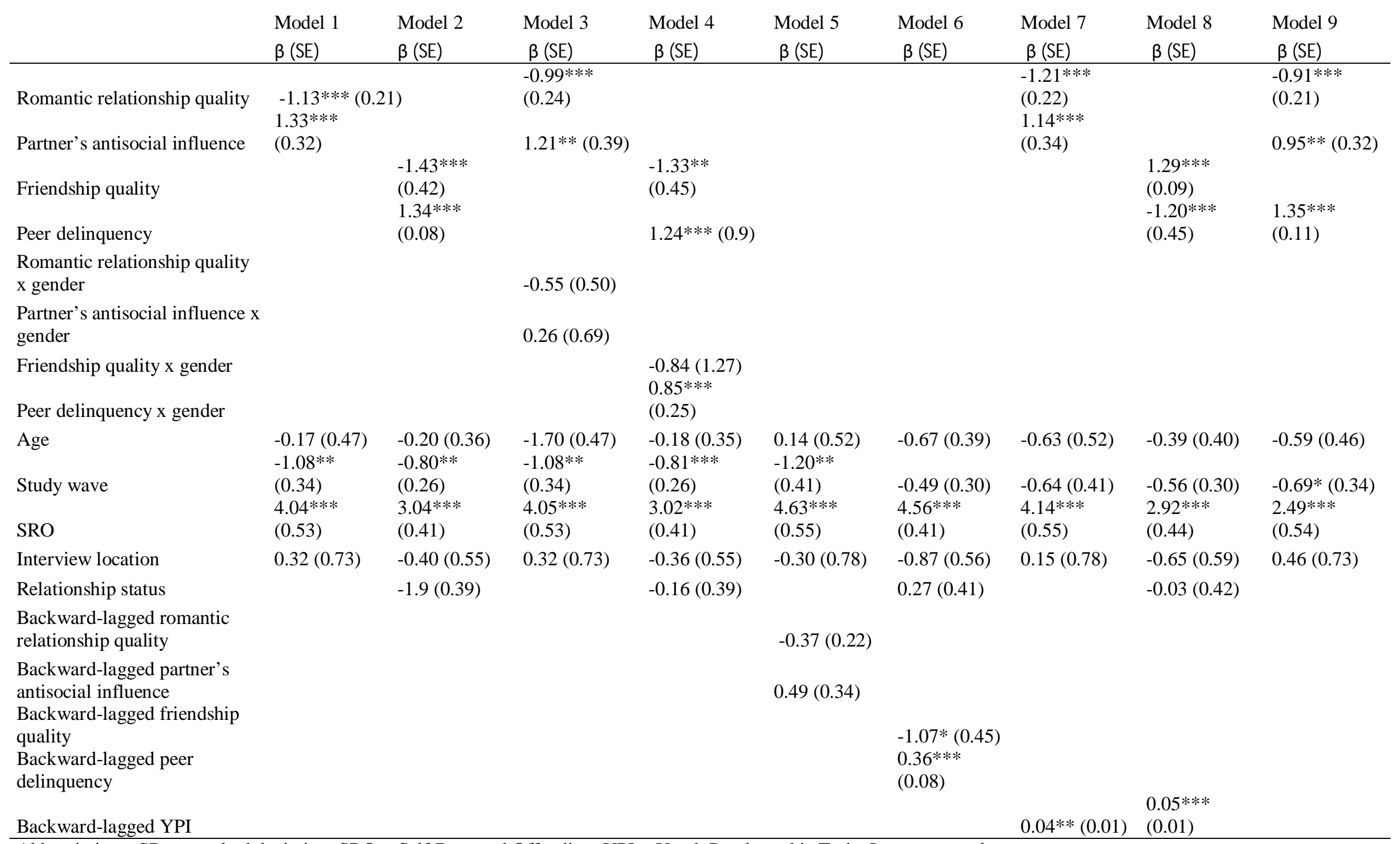

Abbreviations: SD = standard deviation; SRO = Self-Reported Offending; YPI = Youth Psychopathic Traits Inventory total score

Values are B-coefficients for within-individual regressions

$* \mathrm{p}<.05 ; * \mathrm{p}<.01 ; * * \mathrm{p}<.001$ 
Table 3 The within-individual regression coefficients of romantic and peer relationships for psychopathic traits separately in males and females. Associations between backward-lagged independent variables and the outcome variable of psychopathic traits for within-individual and between-individual regressions.

\begin{tabular}{|c|c|c|c|c|c|c|}
\hline & \multicolumn{3}{|c|}{$\begin{array}{l}\text { Regression coefficients } \\
\text { for gender }\end{array}$} & \multicolumn{3}{|c|}{$\begin{array}{l}\text { Regression coefficients for backward- } \\
\text { lagged variables }\end{array}$} \\
\hline Variable & Male $^{\mathrm{a}}$ & Female $^{\mathrm{a}}$ & $\begin{array}{l}\mathrm{P} \text { for } \\
\text { interaction }^{\mathrm{b}}\end{array}$ & $\begin{array}{l}\text { Backward } \\
\text { lagged }^{\text {a }}\end{array}$ & $\begin{array}{l}\text { Backward } \\
\text { lagged }^{c}\end{array}$ & $\begin{array}{l}\text { P for } \\
\text { difference }{ }^{d}\end{array}$ \\
\hline Romantic relationship quality & $-0.99 * * *$ & $-1.55 * * *$ & 0.266 & -0.37 & $-2.99 * * *$ & 0.001 \\
\hline Partner's antisocial influence & $1.21 * *$ & $1.46^{* *}$ & 0.702 & 0.49 & $4.71 * * *$ & 0.001 \\
\hline Friendship quality & $-1.33 * *$ & $-2.30 *$ & 0.508 & $-1.07 *$ & $-6.54 * * *$ & 0.001 \\
\hline Peer delinquency & $1.24 * * *$ & $2.09 * * *$ & 0.001 & $0.36 * * *$ & $2.94 * * *$ & 0.001 \\
\hline
\end{tabular}

${ }^{a}$ Within-individual regression coefficients

${ }^{\mathrm{b}}$ Interaction term calculated via multilevel regression analysis

${ }^{c}$ Between-individual regression coefficients

${ }^{\mathrm{b}}$ Difference between the coefficients calculated via Wald test

$*_{\mathrm{p}}<0.05 ; * * \mathrm{p}<0.01 ; * * * \mathrm{p}<0.001$ 
Appendix 1 Regression coefficients between interpersonal relationships and psychopathic traits and its sub-domains for within-individual analyses across 10 repeated measurement times

\begin{tabular}{|c|c|c|c|c|c|c|c|c|c|c|c|c|}
\hline \multirow[b]{3}{*}{ Romantic relationship quality ${ }^{\text {a }}$} & \multicolumn{3}{|c|}{ Psychopathic traits } & \multicolumn{3}{|c|}{ CU traits } & \multicolumn{3}{|c|}{ GM traits } & \multicolumn{3}{|c|}{ II traits } \\
\hline & \multirow{2}{*}{$\frac{\beta}{-1.13}$} & \multicolumn{2}{|c|}{$95 \% \mathrm{CI}$} & \multirow{2}{*}{$\frac{\beta}{-0.32}$} & \multicolumn{2}{|c|}{$95 \% \mathrm{CI}$} & \multirow{2}{*}{$\frac{\beta}{-0.43}$} & \multicolumn{2}{|c|}{$95 \% \mathrm{CI}$} & \multirow{2}{*}{$\frac{\beta}{-0.38}$} & \multicolumn{2}{|c|}{$95 \% \mathrm{CI}$} \\
\hline & & -1.54 & -0.70 & & -0.44 & -0.19 & & -0.63 & -0.22 & & -0.54 & -0.23 \\
\hline Partner's antisocial influence ${ }^{\mathrm{a}}$ & 1.33 & 0.70 & 1.96 & 0.27 & 0.08 & 0.46 & 0.63 & 0.32 & 0.95 & 0.43 & 0.20 & 0.67 \\
\hline Friendship quality ${ }^{b}$ & -1.43 & -2.27 & -0.60 & -0.67 & -0.92 & -0.41 & -0.65 & -1.07 & -0.24 & -0.11 & -0.42 & -0.20 \\
\hline Peer delinquency ${ }^{\mathrm{b}}$ & 1.34 & 1.17 & 1.50 & 0.29 & 0.24 & 0.34 & 0.56 & 0.48 & 0.63 & 0.49 & 0.43 & 0.55 \\
\hline
\end{tabular}

Values are $\beta$-coefficients (and 95\% confidence intervals) of multilevel linear regressions for psychopathy, Callous-

Unemotional (CU) traits, Grandiose-Manipulative (GM) traits and Impulsive-Irresponsible (II) traits

${ }^{a} \mathrm{n}=6541$ person-observations of 1354 unique individuals

${ }^{\mathrm{b}} \mathrm{n}=9876$ person-observations of 1354 unique individuals 